\title{
Sharing a laugh at others: Humorous convergence in French conversation
}

\author{
Béatrice Priego-Valverde \\ Aix Marseille University, CNRS, LPL, Aix-en-Provence, France \\ beatrice.priego-valverde@univ-amu.fr
}

\begin{abstract}
The aim of this article is to clarify the fuzzy notion of "successful humour". It focuses on humorous sequences in French face-to-face interactions which are both successful and have a same type of target: a collective "Other" (foreign culture, a French or foreign institution, a French or foreign socio-professional group). It will be shown that laughing about/at others (with all the aggressiveness this could imply) is not inconsistent with the necessary collaborative aspect of the conversation.

On the contrary, the necessary collaboration between the participants will be highlighted through analysing humour in two different but complementary ways. Firstly, analysing humour through one specific target (the collective "Other") will show that the participants rely on shared knowledge to display fictitious identities allowing them to construct humour. Secondly, a structural analysis of successful humorous sequences will deepen the notion of successful humour, highlighting two different structures: a two-part structure and a three-part structure. While the terms "successful humour" will be restricted to the former, the notion of "humorous convergence" will be proposed to refer to the latter.

This study is based on 51 successful humorous sequences extracted from three face-to-face interactions audio- and video-recorded in an anechoic room at Aix-Marseille University, France.
\end{abstract}

Keywords: French conversation, humorous convergence, successful humour, alignment, affiliation.

\section{Introduction}

Simply put, successful humour could be defined as a humorous occurrence that receives a positive reaction. However, looking carefully at the data, a more complex picture of successful humour emerges: it appears more as a continuum than as a homogeneous block. Along this continuum, successful humour can be delivered through two structures: a two-part structure and a three-part structure. The former refers to humour which receives a positive answer (such as laughter or positive feedback) from the hearer but without being further developed. The latter leads to a humorous co-construction from both participants. In this article, the terms 
successful humour will be restricted to the two-part structure, while the three-part structure will be considered humorous convergence.

Far from being a simple synonym of successful humour, humorous convergence highlights not only the elements necessary for humour to succeed, but moreover, the elements necessary (and complementary) for humour to succeed in conversation. This notion of humorous convergence enables the analysis of the linguistic mechanisms of humour, taking into account the constraints of the conversation where it appears. It is thus an interactional description and explanation of successful humour. Humorous convergence implies taking into account the interrelation of three elements: (i) the way participants adjust their discourse to each other, (2) the way participants adjust their stance about what is being said, (3) the way participants perform their actions according to their respective interactional roles of speaker and hearer. The first element refers to the "alignment" of the participants; the second refers to their "affiliation" (Stivers 2008). The third one is considered to be a sub-type of "interactional convergence" (Guardiola \& Bertrand 2013) and refers to a humorous co-construction.

Broadly speaking, a humorous utterance can target various referents: the speaker, the hearer, the situation, another third and absent person, or a collective "Other". This last one (the collective "Other") has been selected for the present study and refers either to foreign cultures or to French or foreign intuitions. The main reason for this choice is the fact that it can be hypothesised that a target external to the participants and the ongoing interaction could lead to more instances of humorous convergence because both participants act together against "Others". Indeed, the analysis of the humorous sequences through this target will highlight two different identities displayed and developed by the two participants: 'victim of' and 'better than' the Others.

This article will be divided into four parts. After a brief overview of the literature both in the linguistics of conversation and humour studies, the methodology used will be described. The next part will present some quantitative data. Finally, the last part of the article will be divided into two sub-sections. In the first sub-section, the effects of the specific target of the humorous utterances will be analysed. The other sub-section will be devoted to a structural analysis of humorous sequences, highlighting the two-part structure presented as successful humour, and the three-part structure presented as humorous convergence. The data will be analysed using a corpus-based approach and through various frameworks: Conversation Analysis (for a sequential analysis of the examples), Interactional Linguistics which focuses on actions and activities accomplished by participants in an interaction, and previous work in Humour Studies.

\section{Theoretical background}

In this section, an overview of previous studies both on conversation and conversational humour will be presented in order to highlight the various notions necessary for the description of the notion of humorous convergence.

\subsection{From interactional convergence to humorous convergence}

The notions of "alignment" and "affiliation" (Stivers 2008) have been elaborated through storytelling in conversations. Because storytelling is an asymmetrical activity (Jefferson 1978; Goodwin 1984; Norrick 2007, 2010; Bavelas et al. 2000; Guardiola \& Bertrand 2013), where participants are momentarily distributed as main speaker and hearer, the notions of "alignment" and "affiliation", as defined by Stivers (2008), refer to structural and relational constraints the hearer has to respect in his/her responses for the storytelling to be developed 
and delivered in the best conditions. In this regard, an aligned response maintains the ongoing activity:

When a recipient aligns with a telling, he or she supports the structural asymmetry of the storytelling activity: that a storytelling is in progress and the teller has the floor until story completion. [...] Thus, alignment is with respect to the activity in progress. (Stivers 2008: 34 , emphasis in the original).

Affiliation is a more social or relational concept: "In contrast to alignment, with the term affiliation I mean that the hearer displays support of and endorses the teller's conveyed stance" (Stivers 2008: 35, emphasis in the original). Furthermore, the author argues that affiliation requires alignment.

In line with Stivers' work, Guardiola \& Bertrand (2013) have proposed the notion of "interactional convergence". Far from referring to the simple mirroring of participants' behaviour, which can nevertheless be the case, interactional convergence is broader and refers to both the structural and relational constraints participants have to respect in a conversation: "a convergent sequence requires preliminary alignment and affiliation, associated with similarity (including at the phonetic, prosodic, syntactic, semantic, lexical, and/or discursive levels)" (Guardiola \& Bertrand 2013: 2). Thus, according to what these authors suggest, interactional convergence requires both alignment and affiliation and can be expressed through various activities and devices, such as reported speech and repetition. They also argue, contrary to Stivers (2008), that sometimes "affiliation co-occurs with disalignment", especially in joint fantasising sequences (Guardiola \& Bertrand 2013: 15).

Already implicitly present in Guardiola \& Bertrand (2013) and more elaborately so in Bertrand \& Priego-Valverde (2017), it is added that interactional convergence also requires the ratification of the hearer's answer from the speaker. In line with these two previous studies, it will be argued here that the speaker's ratification is considered to be the keystone of the notion of "interactional convergence". Without it, it could never be argued that the hearer's contribution to the ongoing activity is accepted. Consequently, it could never be argued that both participants have agreed to co-elaborate the discursive sequence in which they are engaged. In other words, without this speaker's ratification, no practicable convergence seems to occur. However, the data show that ratification can be displayed differently. Firstly, the speaker can produce no explicit mark of ratification, but without explicitly rejecting the hearer's utterance. In such a case, the ratification is implicit: "The lack of ratification here is equivalent to a basic acceptance" (Guardiola \& Bertrand 2013: 7). Secondly, the speaker's ratification can be explicit and displayed by discursive markers such as laughter or speech.

Finally, the interactional roles of the participants have to be taken into consideration in order to define humorous convergence. Guardiola \& Bertrand (2013: 2) argue that a sequence is considered convergent "when the interactional statuses evolve towards symmetry between participants". In other words, both the interactional status of a participant and his/her resultant actions are the criteria so that a sequence can be considered convergent. Indeed, having highlighted the specific interactional roles and actions of each participant (the main speaker and the hearer) in an asymmetric activity (storytelling), the authors also showed that sometimes (at particular moments of the storytelling pointed out by the authors), the hearer actively participates in the ongoing activity and the speaker ratifies his/her participation, which is thus considered legitimate. In such sequences, both participants temporarily leave their asymmetric interactional roles, thus creating interactional convergence between them. 


\subsection{Overview of studies on successful humour}

In humour studies, research on conversational humour concerns mainly successful humour, although the term successful is generally implied. It is precisely because the definition of successful humour seems to be taken for granted that a real definition is rarely posited. At the risk of painting a simplistic view of this prolific field, this section will provide an overview of some of the main directions research in this field is taking.

The first one concerns the production of humour by the speaker. These studies focus mainly on linguistic mechanisms of conversational humour, on devices such as puns and punning (see Norrick 1993; Otake \& Cutler 2013), repetition and pinning (see Tannen 2007; Bertrand \& Priego-Valverde 2011; Priego-Valverde 2016), (fictitious) reported speech (see Tannen 2010; Chovanec 2015; Guardiola \& Bertrand 2013; Bertrand \& Priego-Valverde 2011) or the intertextuality of humour (see Kotthoff 2002; Priego-Valverde 2003; Tsakona 2018).

The second type of research concerns the hearer's reactions to humour. These reactions are explored in two complementary ways. While a few studies analyse the range of possible reactions (see Drew 1987; Attardo 2001; Hay 2001; Karachaliou \& Archakis 2018), an increasing number of studies focus on a specific form of successful humour, the humorous coconstruction: "joint joking" (Davies 1984), "fantasy humour" (Hay 1995, 2001), "collaborative fantasy" (Norrick 2000), "co-construction" (Priego-Valverde 2003, 2006), "joint fantasising" (Kotthoff 2007; Stallone \& Haugh 2017), "joint fantasy" (Bertrand \& Priego-Valverde 2011). Among these various studies, some have highlighted a specific structural mechanism of the humorous co-construction: a form of escalation where a word or utterance is a springboard for the next: "scaffolding" (Davies 1984), "overbid" (PriegoValverde 2006; Bertrand \& Priego-Valverde 2011), “one-upmanship" (Priego-Valverde 2006), "incremental structuring and augmentation of unreality" (Kotthoff 2007), "escalating absurd humour" (Béal \& Mullan 2013), "incremental elaboration” (Stallone \& Haugh 2017).

Finally, this focus on the humorous co-construction can also be an example of the third direction in which humour is analysed: its interactional management by the participants (see Straehle 1993; Boxer \& Cortés-Conde 1997; Priego-Valverde 2003, 2007; Archakis \& Tsakona 2005; Holmes 2006; Coates 2007).

A lot of work on failed and successful conversational humour can be reinterpreted using the notions of "alignment" and "affiliation" (Stivers 2008). Studies on responses to humour have dealt with these two notions together. For example, the "po-faced receipts" of teases described by Drew (1987) can be seen as aligned but disaffiliative answers. The four-level model of humour appreciation proposed by Hay (2001) is also a view of aligned and affiliative answers to humour. Studies on failed humour have also highlighted a lack of recognition and/or appreciation (see Priego-Valverde 2009; Bell 2015) from the hearer which can be apprehended in terms of (dis)alignment and/or (dis)affiliation.

Furthermore, many studies have focused on the relational aspect of conversational humour and can be divided into two categories. The studies in the first category deal with the nature of humour raising the question of its aggressiveness, its benevolence or its double nature. They focus both on conversational humour in general and on teasing more particularly (see Straehle 1993; Norrick 1993, 1994, 2003; Boxer \& Cortés-Conde 1997; Priego-Valverde 2003, 2006, 2016; Lampert \& Erving-Tripp 2006; Haugh 2010, 2011, 2014). The second category concerns more specifically the social functions of conversational humour (see Hay 2000; Mills \& Babrow 2003; Norrick 2003, 2008; Priego-Valverde 2003; Haugh 2014, 2017).

Finally, the active participation of the hearer in a humorous co-construction can also be seen as alignment, while his/her affiliation in such a sequence has been regularly depicted as "an as if world" (Priego-Valverde 2003), something "absurd" (Béal \& Mullan 2013), some "improbable, or even impossible, imagined scenarios" (Stallone \& Haugh 2017), a "pretence" (Stallone \& Haugh 2017) which has to be not only accepted but also and above all adopted 
("mode adoption" in Attardo's 2001 words) by the hearer for him/her to be able to react within the same humorous frame and to participate in a humorous co-construction.

But the fact that this mosaic of studies does not really link the characteristics of humour itself to the interactional constraints of the conversation in which it appears leads to a fuzzy picture of successful humour which can be presented as more homogeneous than it really is.

Relying on these previous studies and applying their findings to the analysis of humour, it will be argued here that:

(1) Humour requires the interactional convergence between participants to succeed.

(2) This success can have two structures:

(2a) a two-part structure named successful humour. This structure refers to humour which receives a positive answer (such as laughter or positive feedback) from the hearer but without being further developed. In such a case, the hearer reacts as such and without becoming a speaker. In this structure, the speaker produces humour and the hearer reacts positively. This structure can be presented as follows:

speaker's humour + hearer's positive reaction + speaker's implicit or explicit ratification

(2b) a three-part structure named humorous convergence. In this structure, the speaker produces humour; the hearer not only reacts positively but also plays along with the speaker's humour, producing in turn a humorous utterance linked to the speaker's utterance. Then, the initial speaker outbids in return, which legitimates the hearer's utterance and, consequently, gives the hearer the role of speaker or co-speaker. This active participation from both participants leads to a humorous co-construction. This structure can be presented as follows:

speaker's humour + hearer's active participation + speaker's active participation in return which can be per se a ratification or which can be complemented by another ratification mark such as laughter or feedback marker

\section{Corpus and methodology}

\subsection{Description of the corpus}

The "CID" - Corpus of Interactional Data - (Bertrand et al. 2008) includes 8 one-hour French face-to-face interactions. They have been recorded in an anechoic room at Aix-Marseille University, France. Each speaker was wearing a microphone and both were filmed by a single camera. All the participants were French native speakers and members of the university (students, scholars or staff members).

Two tasks were delivered: half of the participants had to tell unusual stories while the others had to relate stories about professional conflicts they had lived. Despite this protocol and the setting, this data collected is close to what one considers natural conversations because everything was made in that respect: the duration of each recording (one hour) allowing the participants to deviate from the initial task, their familiarity with the anechoic room and, most of all, the fact that the participants in each pair were close acquaintances outside the university. 
For the present article, three interactions were studied; two about conflicts (EB_SR; AP_LJ) and one about unusual stories (AG_YM). All involved only male participants.

Each audio signal was firstly automatically segmented in Inter-Pausal Units (IPU), i.e. blocks of speech bounded by silent pauses over $200 \mathrm{~ms}$, and time-aligned on the speech signal. An orthographic transcription was then provided at the IPUs-level to include all phenomena occurring in spontaneous speech (such as hesitations, repeats, etc.). The transcription used was the Enriched Orthographic Transcription (OTIM projet; Blache et al. 2009). Using Praat (Boersma \& Weenink 2009), systematic annotations related to the different linguistic domains were provided. Only manual orthographic transcription and automatic detection of laughter were used in this study. For each participant, all this information was aligned at phoneme level in order to provide precise information on their timing (co)occurrences. Humorous information was manually annotated.

\subsection{The annotation scheme used for analysing humour}

Various information related to humour was manually annotated using Praat on 15 different tiers and was added to the two tiers showing the IPUs of each participant. In addition, another software, Sppas (Bigi 2015) was used to get quantitative data.

The different annotations made using Praat can be presented as shown in Figure 1 on the following page.

\section{Description of quantitative data}

Before focusing on the specific target "Others", which allows the participants to display specific identities through humour, some quantitative results about the distribution of all the various targets will be presented. Then, a comparison between all the humorous sequences and the humorous sequences concerning specifically the collective target "Others" will be made.

\subsection{Distribution of the different targets}

Five different targets were identified in the data: the speaker $(\mathrm{Sp})$, the hearer $(\mathrm{He})$, the situation $(\mathrm{Si})$, an individual "Other" $(\mathrm{O})$ and a collective "Other" (Os) referring to foreign cultures and French or foreign socio-professional groups or institutions. In this last category, French groups or institutions were categorised together with the "foreign" ones because the participants clearly considered themselves as not belonging to them. Here are some examples highlighting the fact that the humour targeting these groups or institutions is mostly based on cultural stereotypes, whether true or not true: English food is awful, French administration is complicated, Quebeckers speak strange French, American cheeses look like candles, experimenters are profiteers.

\subsection{Comparison of the humorous sequences}

On the basis of the three interactions presented above, 130 humorous examples were extracted and, among them, 61 examples of humour about a collective "Other" were identified. 10 were occurrences of failed humour and were not analysed. Thus, the present analysis concerns 51 examples. Figure 2 shows the total number of humorous sequences in the three entire conversations. 


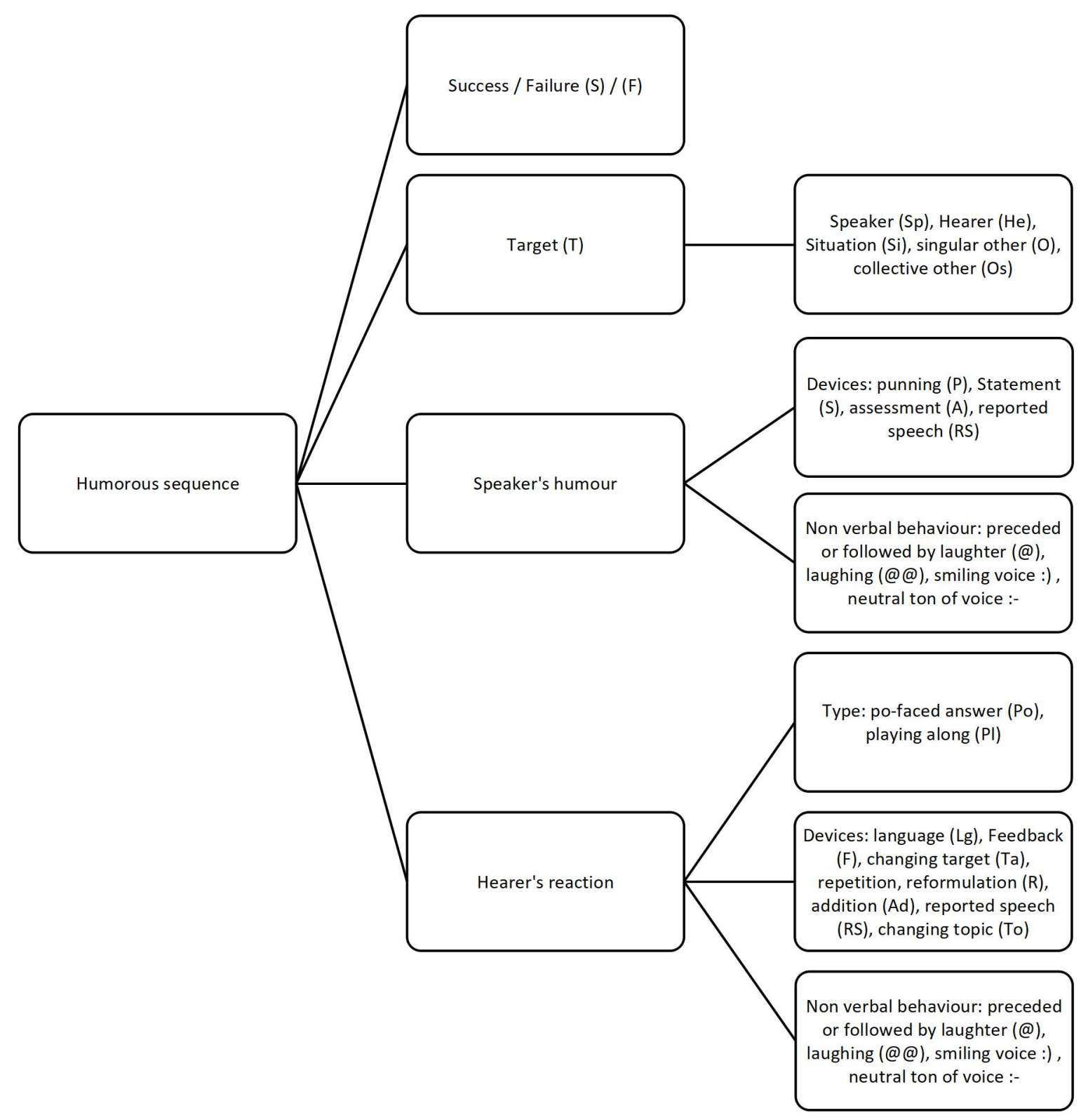

Figure 1. Annotation scheme for the humorous sequences

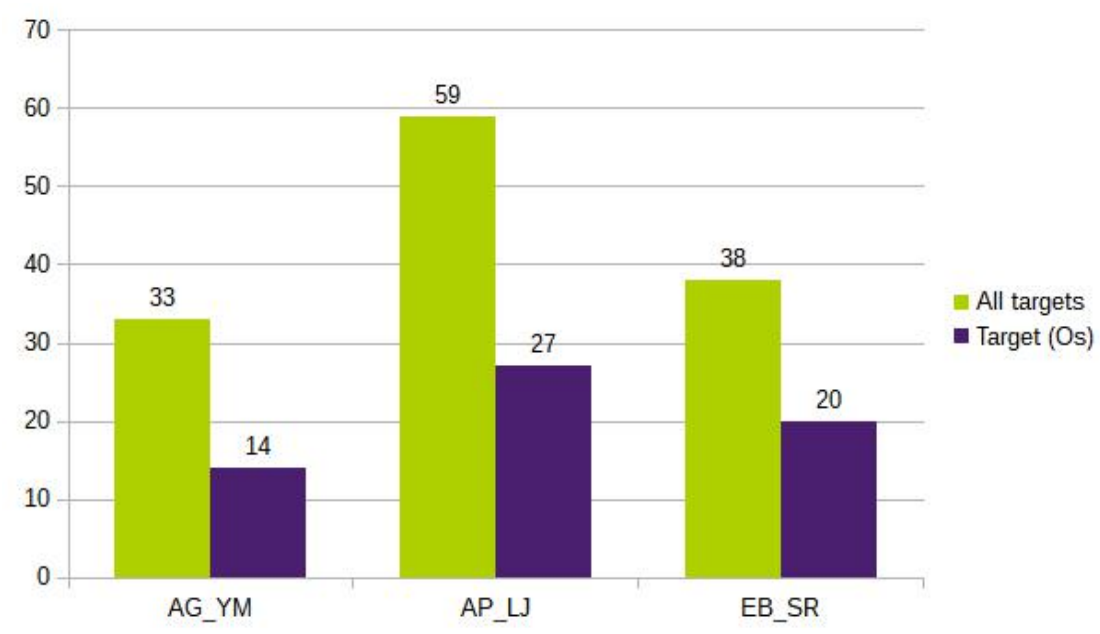

Figure 2. Number of humorous sequences (all targets vs. target "Others")

Open-access journal | www.europeanjournalofhumour.org 
- A high discrepancy between the three interactions can be observed concerning the total amount of humorous sequences: AP and LJ produced almost double the humour of the other participants.

- However, the amounts of humorous sequences about "Others" were more homogeneous. They represented more or less half of all humour occurrences. This result can be explained by the task, which was to tell unusual or conflict stories. Such storytelling may often lead to other referents being involved.

- Still, the task explains the high representation of the target "Others" more than it explains the presence of humour itself. Indeed, AP_LJ and EB_SR had conflicts to tell and AG_YM had unusual stories. If more humour could have been expected in telling unusual stories, more humorous occurrences would have been present in AG_YM conversation and fewer in the two other conversations. Yet, the results are the exact opposite: the least prolific providers of humour were AG_YM.

Figure 3 shows the total duration of the humorous sequences in the three interactions.

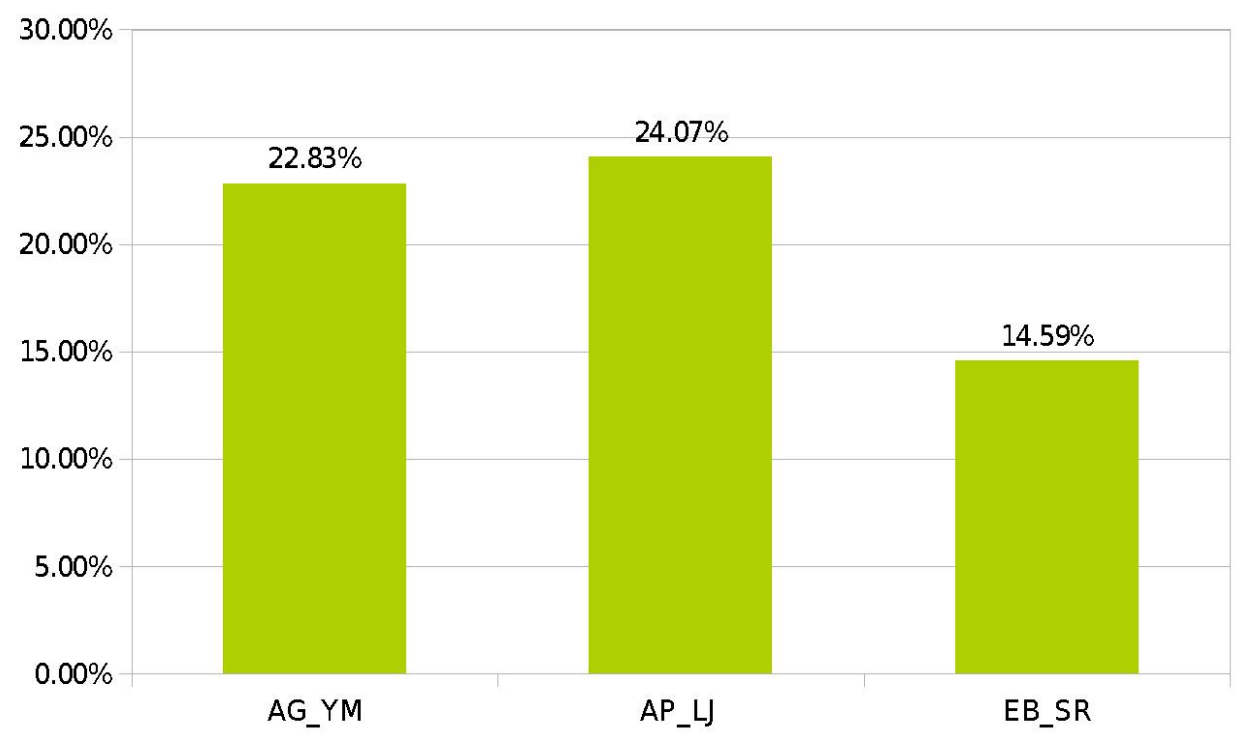

Figure 3. Total duration of the humorous sequences

The total time participants spent engaged in humorous sequences modulates the results concerning their total amount and shows a more homogeneous picture. The biggest difference between the two results concerns AP_LJ. Paradoxically, the same reason can explain that AP and LJ remain the most prolific participants and that they do not spend significantly more time than the others producing humour. This reason is the nature of their relationship. Indeed, even though all the participants were matched according to their friendship outside the university, AP and LJ were the closest friends, sharing not only their work at the university but also a lot of their free time. Thus, if it can be hypothesised that their closeness facilitates the emergence of humour, it can also be considered that this closeness could have impacted the way they dealt with the task. Indeed, AP and LJ diverged from the task more often than the other participants. Producing fewer storytelling sequences, they produced more conversational humour - generally inserted in shorter sequences than humour in the form of storytelling.

Furthermore, comparing the three interactions, the results highlight a low impact of the nature of the stories participants had to tell, insofar as it is insufficient to explain the discrepancy of the results between EB_SR, on the one hand, and AG_YM and AP_LJ, on the other. Indeed, if it could be hypothesised that telling conflict stories - what EB and SR had to 
do - does not facilitate the emergence of humour, thus such a hypothesis cannot explain why AP and LJ, who had the same task, spent as much time producing humour. Similarly, the nature of the stories told does not explain the small discrepancy in the results between AP_LJ and AG_YM, who had to tell unusual stories.

Figure 4 shows the humorous sequences involving the collective "Other".

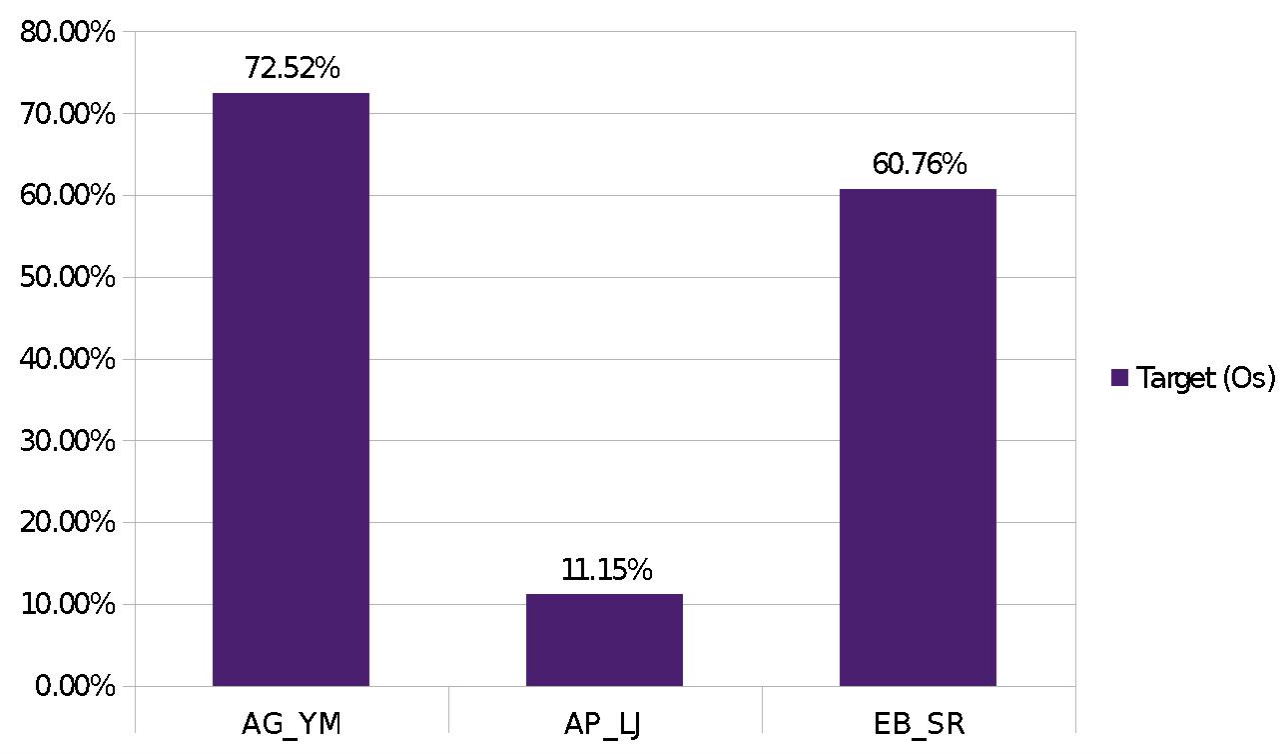

Figure 4. Duration of the humorous sequences with the target "Others"

This figure specifically shows the duration of humorous sequences targeting "Others". The percentages presented here are calculated on the basis of the total duration of the humorous sequences and not on the total duration of each interaction. In other words:

- AG_YM spent $72.52 \%$ of their humorous sequences targeting "Others";

- AP_LJ spent $11.15 \%$ of their humorous sequences targeting "Others";

- EB_SR spent $60.76 \%$ of their humorous sequences targeting "Others".

A very high discrepancy can also be observed, when comparing AP_LJ and the two other interactions. If such a difference is indeed remarkable, it also seems to confirm the impact of the nature of the relationship between the participants. The very low duration of humorous sequences against "Others" in AP_LJ could be explained, here again, in terms of their closeness. It is probably because AP and LJ are the closest friends that they deviate from the task more often than the other participants, thus producing more conversational humour than humour inserted into long storytelling.

\section{Sequential analysis of some examples}

In this section, 5 examples will be analysed in two different ways. Considering the specific nature of the targets involved in the humorous sequences observed (i.e. "Others"), a first breakdown of the examples can be made according to the humorous identities the participants displayed through humour. A second breakdown, this time a structural one, will be proposed, distinguishing between two different categories: successful humour and humorous convergence. 


\subsection{Identities displayed through humour}

Two distinct identities were displayed through humour in the 51 examples. The first identity is 'victim of'. The participants present themselves as victims of various institutions or persons. For instance, they appear to be victims of the incompetence of some administrative agents or of the dishonesty of some professional environments. In such sequences, they are not engaged in a genuine complaint sequence, but they address jocularly negative criticisms and reproach to those "Others" (Haugh 2017). The second identity is 'better than'. The participants produce humour where "Others" are not only different - which is sometimes funny per se for the participants - but also "inferior" in some way. Displaying this identity, participants mostly tease "Others" and laugh at them, pointing out their (supposed) shortcomings, such as the bad quality of British or American food, the sluggishness of public servants, the arrogance of soccer players.

Both identities can be displayed regardless of the target (foreign cultures and socioprofessional groups). Likewise, the same humorous devices such as comparison, exaggeration, pejorative lexicon, endorsement of the humorous utterance on cultural knowledge or stereotypes can be used to display the two identities. As a form of humour, teasing also allows the two identities to be displayed. All these common points are not surprising because, whatever the identity displayed, participants remain humorous. In other words, to perform negative or at least delicate social actions can be humorous; likewise performing these social actions through humour is also possible. This is in line with previous research depicting humour as a "social lubricant" (Priego-Valverde 2003: 147) allowing the participants to address a delicate social action like a reproach. Haugh (2017: 148) analyses this specific function of humour, hypothesising that "playful actions may disguise non-playful or serious actions". In the same study, the author also analyses joint fantasising sequences arguing that "sensitive social actions, such as complaints, may also be modulated through episodes of joint fantasising" (Haugh 2017: 159). However, it should be noted that there is a difference with the previous studies: in the examples analysed in this article, this social function of humour is enacted when participants produce humour about an absent third party and not about one of them.

It is worth noting here one major particularity observed in the examples analysed: selfdeprecating humour is only present with the 'victim of' identity, while it is absent with the 'better than' identity. This finding highlights the fact that self-deprecating humour is a doubleedge sword: on the one hand, the speaker hides the real target behind an obvious one (himself), which allows him to diminish, in appearance, its negative charge (Priego-Valverde 2007). On the other hand, laughing about himself and presenting himself in a bad position allows the speaker to accentuate his image of victim, which exacerbates the negative criticisms. This double nature of self-deprecating humour is especially significant when, as in the examples presented here, it involves an absent target. In this case indeed, self-deprecating humour allows the speaker to attract sympathy from the hearer. It is thus not surprising that some examples of self-deprecating humour lead to a joint fantasising sequence.

Finally, humorous convergence can appear through the two identities, which highlights the fact that targeting "Others" allows participants to stand together against the target.

The 'victim of' identity appears in 31 examples and the 'better than' identity appears in 20 examples. However, one can consider that in some cases both identities are displayed, even though one is more obvious than the other. Below, an example of each identity is presented. 
(1) The 'victim of' identity: Tu décoinces / You loosen up

1155 mais ça fait une heure là @

$2138 @$

$3156 @$

4139 du coup on (re)garde plus ouais

$5 \quad 157 * \mathrm{p}(\mathrm{u})$ is ouais [puis, pis] c'est dur du coup de

6158 de discuter sur commande comme ça

7141 ah ben ouais mais ça

$8 \quad 159$ et

9142 non e(lle)s au(r)aient dû au lieu d'emm(e)ner du des croissants e(1l)es auraient dû

10 dre euh [je sais, ch] pas une ou deux bières

$11160 @$

12143 après après deux [bières, bièreu] là à neuf heures c'est bon $\mathrm{j}(\mathrm{e})$ crois que

13162 on a(v)ait plein d'anecdotes ouais

14144 tu

15145 des euh

16146 tu décoinces

17147 ouais + bon insolite alors insolite qu'est-ce qu(i) peut y avoir

1 YM: but it's been one hour now @

2 AG: @

3 YM:@

4 AG: thus we don't look at it anymore yeah

5 YM: and yeah and it's hard thus to::

6 YM: to discuss on request like that

7 AG: ah well yeah but $\underline{\text { it's }}$

8 YM: it's uh

9 AG: no they should have/ instead of bringing some croissants they should have taken uh I

10 don't know, one or two beers

11 YM:@@@yeahoneuh@@@

12 AG: after after (smiling voice) two beers here at nine it's ok I guess

13 YM: we had many stories yeah

14 AG: you

15 AG: some uh

16 AG: you loosen up

17 AG: yeah + well unusual so unusual what can it be [...]

YM has just finished telling a story about one of his acquaintances. The two participants are searching for new topics they could develop. YM's exclamation (line 1) appears after a long silence of 3' 6 seconds. YM frames humorously his utterance with laughter at the end and exaggeration (the recording began only less than 8 minutes before). This exaggeration works both as a clear signal of humour (they do know they have not spent one hour, yet) and as a clue of YM's feelings, which could be a kind of fatigue or dismay because he does not know what to speak about. It is thus self-deprecating humour because he laughs about his own uncomfortable position. At that time, he does not position himself and his partner as victims of the experimenters, yet, but only as a participant who feels like time is passing slowly. AG aligns and affiliates with YM by laughing (2), which is ratified by YM (3) with laughter in 
return. In line (4), AG rebounds only on what was explicitly verbalised by YM: he does not have the notion of time. Sharing the same impression about the situation they are experiencing, he affiliates with YM's stance or, more precisely, with what he has heard in YM's stance, i.e., his fatigue or dismay framed humorously. In lines (5-6), aligning with AG (yeah), YM explicitly verbalises the reason why he feels uncomfortable (it's hard to discuss on request like that). A target is implied beyond his utterance: the experimenters who "torture" at least him, and probably both of them, leaving them in the anechoic room. In lines (7-8), the participants agree with each other and try to find words to express their feelings. In (9-10), AG designates the target implied by YM, without naming them (they, i.e., the experimenters), considering them to be the cause of their discomfort. In doing so, he aligns with YM, finding the cause of their discomfort. He also affiliates with him, sharing YM's stance, both YM's humour and discomfort. Like YM, AG stages himself as a victim of experimenters who did not treat them correctly: while the experimenters bring them breakfast, he would have preferred beers. His utterance clearly expresses a reproach to the target (they should have) but jocularly (cf. Haugh 2017): it is too early in the morning to have some beers and they are at work. Asking for some beers is also a way, at least, to insist on their discomfort or even to humorously present themselves as alcoholic. As AG points out, if they had drunk beer, they would have loosened up and felt more comfortable to address the task. He thus targets the experimenters through self-disparaging humour. Finally, the setting helps him to frame his reproach humorously: he knows that the experimenters - who are good acquaintances of his are in the next room, listening to them. His utterance is thus a "communication trope" (originally "trope communicationnel", Kerbrat-Orecchioni 1986) addressed to them. In line (11), YM aligns and affiliates with AG by laughing and repeating "one [beer]". In (12), insisting on the time of day (at nine), AG accentuates the gap between the early hour and his request for alcohol and, therefore, creates self-deprecating humour. In line (13), YM aligns and affiliates with AG by continuing his utterance and also implying the effects of being drunk. In (14-16), AG ends this humorous sequence with a last utterance where he clearly verbalises the effects of alcohol, i.e., being uninhibited. YM's utterance in (13) and the beginning of AG's in (14) are produced in overlap. This overlap can be considered a clue of their convergence because they want to express the same idea at the same time. In line (17), AG returns to a serious frame, rephrasing the task given by the experimenters.

In this example, the participants jocularly display the image of victim of the experimenters. They use self-deprecating humour to place themselves in a difficult situation, and they target the experimenters as responsible for it. Both the form of humour (selfdeprecating humour) and the humorous devices used, that is, exaggeration or pretence, frame jocularly the reproaches they address to the experimenters (cf. Stallone \& Haugh 2017). Finally, sharing the same target, which is external to them (i.e. the experimenters), facilitates their interactional convergence, and more precisely here, their humorous convergence. Similarly, their humorous convergence accentuates their identity of 'victim of': they stand together against the experimenters.

It is worth noting here that even if reproaches could be more reasonably expected when participants display a 'better than' identity, this example is clearly an example of the 'victim of' identity. Using self-deprecating humour, the participants are looking for sympathy. At no moment did they imply that they would have done better than the experimenters if they had been in their shoes.

The next example illustrates the display of the 'better than' identity': 
(2) The 'better than' identity: À dos d'âne / On the back of a donkey

1 EB 323 et c'est un gros écolo apparemment

2 EB $324 *$ p(u)is i(l) vit dans une euh dans une maison euh

3 EB 325 il a ach(e)té une ruine euh

4 EB 326 y a(v)ait même pas d(e) route [etc,etcétéra] ça fait vingt ans qu'i(l) vit là-bas avec

5 ses enfants

6 SR 212 et ouais

7 EB 327 et il a pa- il a pas l'électricité

8 EB 328 (en)fin pas l'électricité il a pas euh il est pas branché au réseau [\$E.D.F., S/\$,

9 édéaiff]

10 SR 213 ben euh

11 SR 214 si s'i(1) est au [\$C.N.R.S., S/\$, céhènhairesse] s'i(1) est au [\$C.N.R.S., S/\$,

12 céhènhairesse] il a $1(\mathrm{e})$ temps $\mathrm{d}(\mathrm{e})$ faire des travaux

13 EB 329 il a des piles euh

14 EB 330 ouais c'est ça c'est

15 EB 331 [c(e), ss] que j- [c(e), ss] que exactement [c(e), ss] que je pensais

16 SR 214a@

17 EB 332 ah ben ça va

18 EB 332a@

19 EB 333 @i(l) peut la construire a(v)ec des pierres euh spéciales sa piscine @

20 EB 334 sûr qu(e) t'as 1(e) temps d(e) monter à dos d'[âne, aneu]

21 EB 334a@

1 EB: and he's a hardcore environmentalist apparently

2 EB: and he lives in a uh in a house uh

3 EB: he bought a ruin uh

4 EB: there wasn't even a road etc he's lived there for 20 years with his children

5 SR: eh yeah

6 EB: he doesn't have he doesn't have electricity

7 EB: well no electricity he's not connected to the electrical grid

8 SR: well ++ if if

9 SR: if he's at the CNRS he has time to fix up his house

10 EB: he has batteries uh

11 EB:@@yeah that'sit@@@that's

12 EB:@@it's exactlywhat I thought@@

13 SR:@ (until the end, line 18)

14 EB: (smiling voice) ah all right @

15 EB:@@he can build his pool with special stones@@

16 EB: (smiling voice) sure you have time to get up on the back of a donkey [he can take his 17 sweet time]

18 EB: @

EB is speaking about a researcher in Cosmology he heard on a radio station. The excerpt begins when EB presents the researcher as a hardcore environmentalist. In lines 1-7, EB is more engaged in a gossip sequence than in humour (no verbal or non-verbal clue can justify humour). Various targets are involved in EB's gossip. The first one is a third absent person explicitly named before the transcript. But this specific person leads to target another social 
group to which he belongs: the hardcore environmentalists. Until line 7, EB is gossiping about the researcher being a hardcore environmentalist, exaggerating his way of living. He exaggerates the state of the target's house, presenting it as a ruin with no electricity. In the meantime, SR, the hearer, produces some feedback, taking into account EB's utterances. He thus aligns with EB but his affiliation is questionable: does he really share the gossip stance initiated by EB? Does he really agree on targeting the environmentalists? Line 9 shows that while SR aligns with EB by also talking about the house, he disaffiliates with him by introducing a humorous frame instead of a gossip one. SR also changes the target: because the researcher is also a public servant, public servants become the new targets. The humour he thus produces is, on the one hand, directly linked to EB's utterances (the ruin the researcher bought) and, on the other hand, targeting another socio-professional group, namely public servants, activating the cultural stereotype according to which public servants have a lot of free time. EB reacts positively to SR's humour. He aligns and affiliates through accepting the new target. At first (lines 11-12), he does not play along with SR's humour but he produces a po-faced answer displaying his agreement and showing he shares the same stereotype (which is ratified by SR's laughter in line 13). Then, in lines 16-18, he overbids SR's humour, exaggerating the free time the researcher has to build his house. This overbid is ratified by the laughter SR produces from line 13 to the end.

Thus, EB not only accepts the change of frame (from gossip to humour), but he also accepts the new target introduced by the hearer, SR (it's exactly what I thought, line 12). This acceptance can be explained by the fact that the humorous utterances EB produces in lines 1516 could also match the first targets he has himself introduced, i.e., the environmentalists. He acts as if he accepted SR's new rules of the game, but without disavowing his previous utterances.

This humorous sequence is based on a cultural stereotype: public servants have so much free time that they can build their own house, even stone by stone. This stereotype is known and shared by both participants. This could explain why SR's humour succeeds, i.e., why EB aligns and affiliates with SR's humour, even though SR produced a disaffiliated answer in order to produce his humorous utterance.

In general, these two examples show the way various types of shared knowledge may be used as relevant leverage to humorously display an identity. While both examples are based on cultural stereotypes, in example (1) the participants also rely on their close relationship between each other and the experimenters.

\subsection{Structure of the humorous sequences}

In this sub-section, the structure of humorous sequences will be analysed. Two different structures have emerged from the analysis of the data. The first one is successful humour, that is, a two-part structure where humour succeeds without being developed. The second one is humorous convergence, that is, a three-part structure where both participants collaborate to the development of humour until they create a joint fantasising sequence.

\subsubsection{Successful humour: A two-part structure}

A two-part structure can be considered the simplest form of success and can be presented as follows: S's humour + H's positive reaction (+ implicit/explicit ratification). The final part of the humorous sequence can be initiated either by the hearer, after reacting positively, or by the speaker, as in example (3). 
(3) Baisse ton son / Turn down the volume

1 EB 746 ou c'(é)tait- i(ls) f(ai)saient des tests euh (en)fin genre euh i(ls) euh [i(ls), iz] d-

2 décrivaient comment fonctio- (en)fin [ils, iz] étaient en train de euh travailler sur un

3 logiciel mais c'était juste euh

4 EB 747 montrer comment 1(e) logiciel fonctionnait quoi

5 EB 748 puis à la limite on av- [ils, iz] avaient pas b(e)soin d'entend(re) correctement l(e)

6 truc quoi

7 EB 749 bon j'ai pas osé leur demander pa(r)ce que euh

8 EB 750 [parce que, passi] y avait des chefs

9 EB 751 que tu euh dis pas au chef euh

10 SR619a@

11 EB 752 §oh§

12 EB 752a@

13 EB $753 \mathrm{t}(\mathrm{u})$ baisses ton son

14 SR619b@

15 EB 754 et donc voilà

1 EB: or it was they were testing uh well like uh they were describing how work well they

2 were working with software but it was just uh

3 EB: show how the software worked so

4 EB: and at the end we didn't they didn't need to hear correctly the stuff well

5 EB: well I didn't dare ask because uh

6 EB: (smiling voice) because the CHIEFS were there

7 SR:@

8 EB: because you don't tell the chief uh::

9 EB: §oh

10 EB:@

11 EB: (smiling voice) §turn down the volume§

12 SR:@

13 EB: and that is

EB explains to SR that previously, he lived a conflicting situation with noisy co-workers sharing the same open-space office. But, and this is the trigger of his humour, he did not dare ask them to be more silent because these persons were his superiors, which EB says in line 6 with a smiling voice. Presenting himself as trapped by social norms despite the discomfort he felt, EB frames his utterances as self-deprecating humour, displaying an image of 'victim of'. SR laughs (line 7): he aligns and affiliates with EB's humour. His laughter can be explained by the fact that the situation is related as laughable. Then, EB accentuates this laughable situation and then the self-deprecating humour (lines 8-11). Therefore, from laughable, the situation he depicts becomes incongruous when EB stages himself reprimanding a superior. And precisely, EB plays with this incongruity and accentuates it with a specific humorous device: he elaborates a pretence by producing a fictitious reported speech staging himself talking to his superiors in a very rude way (see the interpellation $o h$, line (9) and the use of the possessive adjective your (line 11) which is verbalised in French as a tutoiement (i.e., in a very informal way). SR laughs again (line 12) and the humorous sequence is closed by the speaker himself.

All along the sequence, SR is laughing without ever contributing to EB's humour. He reacts as a hearer and never asks to become a speaker who could have proposed a humorous 
utterance. As pointed out in section 2, this example shows that laughter from the hearer can facilitate the success of humour, but remains insufficient to further develop it. Such development will be presented in the next sub-section.

\subsubsection{Humorous convergence: A three-part structure}

Here, the success of humour deploys in a three-part structure. Humour is developed by both participants being, at that time, co-speakers. It is thus humorous convergence which leads to joint fantasising. And humorous convergence leading to joint fantasising involves the active participation of both participants. As shown in the previous example, the hearer's laughter leads to the success of humour but not necessarily to its development. In this sense, laughter is cooperative but not collaborative (Davies 1984). However, in a three-part structure, the speaker produces humour, the hearer actively reacts, and the speaker actively reacts in return, i.e. not only taking into account the hearer's humorous utterance as such, but using it as a springboard to pursue jointly his humorous production. It is thus an "incremental elaboration" (Stallone \& Haugh 2017). Such active participation in return may both function as ratification per se and be associated with another ratification mark such as laughter or a feedback marker.

It is worth noting here that, in this study, humorous convergence and joint fantasising (or humorous co-construction) are used as synonyms. However, while the notion of joint fantasising focuses more on the escalation process of the sequence, humorous convergence exceeds this description to show the impact such escalation has on the participants' interactional roles. In other words, the notion of humorous convergence highlights the symmetrical position the participants have while they are co-constructing humour.

Two kinds of co-constructions have emerged. The first one is a playful development of the ongoing topic and the second one leads to the creation of a side sequence - which constitutes "a break in the activity" (Jefferson 1972: 294) - disconnected from the ongoing topic.

\section{Playful development of the ongoing topic}

(4) Les opérateurs écossais / The Scottish operators

1 YM $851[\ldots]$ français y a(v)ait pas

2 AG $787 \mathrm{hm}$

3 AG 788 mh d'accord

4 YM 852 y avait espagnol donc i(ls) m’ont filé euh @ une interprète espagnole quoi putain

5 c'(é)tait pire que tout quoi j'arri(v)ais

6 AG789@

7 AG790@

8 AG791@ mais tu (1)e par(les) espagnol un peu

9 YM 854 non du tout @ [tu vois, tcha]

10 AG $792 @$ @on c'(é)tait vaut mieux l'anglais alors hein

11 YM 855 s(e) sont dit §bon c'est plus proche que l'anglais@ allez + (vou)s allez vous

12 démerder avec ça quoi§

13 AG794@

14 AG795@

15 AG 796 c'est v- sont voisins ouais

16 YM 857 ouais

17 YM 858 son voisin là putain euh 
18 YM 859 j'arri(v)ais pas oh p(u)tain et [puis, pis] les chiffres ouais ép(e)ler les noms et

19 tout

20 AG $797 \mathrm{mhhm}$

21 YM 861 ça quand i(l)s eux i(l)s te balancent les chiff(res) c'est super [rapide, rapideu]

22 YM 863 (en)fin bon c'est euh

23 YM 864 tu tu [galères, galèreu] mais c'est bon c'est marrant quoi

1 YM: French language wasn't available

2 AG: $\mathrm{mh}$ ok

3 YM: there was Spanish so they gave me uh@@@a Spanish interpreter goddammit it

4 was worse than everything I couldn't@@//

5 AG: @

6 AG:@

7 AG: @ but do you speak Spanish a little

8 YM: no not at all@@@you see@@

9 AG:@@well it was +English is better souh@@

10 YM:@@they told themselves §well it's closer than English§@@@ @figure it out§

11 AG: @

12 AG:@

13 AG: §it's nei- (smiling voice) they are neighbours $\S$ yeah

14 YM:@yeah@@

15 YM: (smiling voice) §they're neighbours $\S$ goddammit uh

16 YM: I couldn't manage it oh goddammit and then the numbers yeah spell the numbers

17 and so on

18 AG: $\mathrm{mhm}$

19 YM: when they give you the numbers it's very fast

20 YM: well it's uh

21 YM: it's hard but well it's funny

YM lived in Scotland for one year after his $\mathrm{PhD}$. He faced linguistic difficulties, especially when he had to make a phone call to administrative services. The excerpt begins when YM, the main speaker, begins his humorous storytelling, explaining his situation. At that moment, AG, the hearer, provides an appropriate response (Jefferson 1978). He aligns with YM, producing feedback, taking into account what YM has just said, and allowing him to go on telling his story. YM keeps going (lines 3-4) and produces the "climax" of his story (Selting 2017). By laughing (lines 5-6), AG aligns and affiliates with YM, recognising and sharing the humorous stance introduced by YM, but not, as the next lines will show, his self-deprecating humour introduced with the words it was worse than everything (line 4). Indeed, in lines 7-9, the participants return momentarily to a serious frame, a short "aside"1 (Selting 2000) where AG needs to clear up a potential ambiguity: YM's humorous utterances can be also selfdeprecating only if he does not speak Spanish. Confirmation being given that YM does not speak Spanish (line 8), humour can go ahead (line 10). In lines 10-15, the participants are producing a joint fantasising sequence where YM does not disappear completely as the target, but where he is sidelined by another one: the Scottish operators. In line 10, YM elaborates a pretence producing a fictitious reported speech staging the Scottish operators talking to him and justifying that they gave him a Spanish speaker as interlocutor by the fact that all Romance languages are similar or close enough to be interchangeable. Because this fact is considered erroneous by the participants, it represents the basis of the joint fantasising. In lines 
11-13, AG once again aligns and affiliates with YM. He laughs and plays along with YM's humour. Moreover, he plays along producing the same humorous device: the same fictitious reported speech built on the same semantic field "closer/neighbour". Here, the participant who uses the reported speech is not the speaker but the hearer who was not present in the situation told by the speaker. His reported speech has thus an "inventive" function (Vincent \& Dubois 1997) displaying affiliation with the speaker. It is thus an "Echo Reported Speech" (henceforth ERS, Guardiola \& Bertrand 2013). ${ }^{2}$ YM ratifies the ERS first in line 14 with a positive feedback and then in line 15, repeating AG's utterance (they are neighbours) entering in AG's ERS. After that, YM goes back to his story, telling his linguistic difficulties.

This example illustrates how a joint fantasising sequence may maintain and further develop the ongoing topic. Participants jointly highlight the point of the main speaker's story: he faced linguistic difficulties the first months he spent in Scotland.

This example shows all the necessary ingredients of a convergent humorous sequence. While humour is inserted in a longer storytelling sequence, the hearer displays appropriate responses (laughter and feedback) until the climax, allowing the teller to pursue his telling. He thus begins to align with the speaker and then also affiliates after the production of the climax. $^{3}$ But despite his affiliation to the humorous stance, AG needs to affiliate even more with the self-deprecating humour produced by the teller, which leads to an aside in order to know whether YM, the speaker, actually speaks Spanish, i.e., in order to recognise as such self-deprecating humour. This aside highlights both the discursive task of a teller which is "to make recognisable the climax of the story in order to enable the recipients to infer when to respond as made relevant and thus co-construct the climax and hence the story" (Selting 2017: 2) and his deficiency in this specific case. Indeed, if YM sufficiently framed his telling as humorous by laughing (which is recognised by AG), he did not give the key point to make his self-deprecating humour recognisable. Yet, when humour is anchored onto one of several personal characteristics of one of the participants (of himself when he uses self-deprecating humour), the speaker has to make sure that this characteristic is at least known and perhaps shared by the hearer. Otherwise, humour or, in that case, the self-deprecating aspect of humour, cannot be perceived. This point makes the proximity between the participants both a prerequisite for humour to succeed and a consequence of humour (Priego-Valverde 2003, 2006). From line 10 to the end, all the information being provided and the climax of the storytelling itself being delivered, the participants are no longer in an asymmetrical relationship but in a symmetrical one, which allows both of them to equally participate in the elaboration of the humorous sequence.

This joint fantasising sequence is elaborated as a "joint pretence" (Stallone \& Haugh 2017) where Scottish operators are depicted as more ignorant than they probably are. This imaginary world is built, on the one hand, on the same semantic field used and shared by both participants (neighbour/close) and, on the other hand, with reported speech and ERS. Using the same devices reinforces the humorous convergence between the two participants and contributes to the success of joint fantasising.

\section{Creation of a side sequence}

The last example is a joint fantasising sequence which creates a side sequence disconnected from the ongoing topic.

\section{(5) Le colporteur / The peddler}

1 LJ 778 [...] et ça ressemblait à un oiseau photocopié quinze mille fois un peu colorié

2 AP $842 \mathrm{a} *$

3 LJ 779 tu dis $\S$ mais attends un gamin il fait ça @ déjà tu lui files deux baffes quoi $\S$ 
4 AP $843 \mathrm{mh}$

5 AP $844 \S$ qu'est-ce que ça t'évoque $\S$

6 AP $845 \S$ eh ben là disons que euh je pense plutôt à ma mère euh $\S$

7 LJ 780 et euh et

8 AP $846 @$ et à mon attirance euh

9 LJ 781 et en plus euh tu aimes les films de gladiateurs

10 AP 846a@

11 AP 847 oui

12 AP $848 \S$ oui as-tu déjà été dans les bains turcs euh $\S$

13 LJ 782 et en plus euh @

14 LJ783@en plus ce type là il est

15 LJ 784 je l'ai vu faire une fois [...]

1 LJ: [...] and it looked like a bird copied 15000 times and a little coloured

2 AP: @

3 LJ: you say but wait a child he does that @@you give him two slaps@@@

4 AP: hm

5 AP: §what does it evoke for you $\uparrow \S$

6 AP: $\S$ well here let's say that uh:: I mostly think of my mom uh $\S$

7 LJ: and uh and

8 AP: @ §and at my attraction uh $\S$

9 LJ: and also uh (smiling voice) §do you like gladiators movies $\uparrow \S$

10 AP: @

11 AP: $y$ yes $\S$

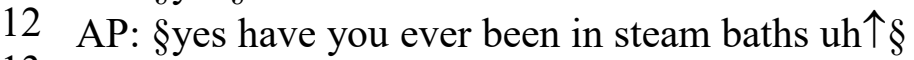

13 LJ: and also uh@

14 LJ:@@@and also this guy is@@

15 LJ: (serious tone of voice) I saw him once [...]

LJ, the main speaker, tells a story about peddlers who want to sell their own drawings on the street. Considering them scammers, LJ frames humorously his utterance (3) with laughter and compares these drawings with those of a child: so badly made that even made by a child, they would look awful. In line 4, AP aligns with LJ, producing short feedback, waiting for the follow-up. But immediately after (lines 5-6), AP, still staying within the humorous frame, changes its devices. Leaving out the comparison to the children, he creates a new world, not only imaginary and incongruous but also barely connected with LJ's utterance. The drawings, not even verbalised, are the tenuous link. Thus, he produces a fictitious reported speech staging a therapist asking his/her client what these drawings evoke to him/her. Technically, AP does not interrupt LJ but takes advantage of LJ's breathing pause. But, as the next lines show, LJ has not finished telling his story. Thus, at that time, one can consider that AP disaligns but affiliates with LJ, staying within a humorous frame. But line 7 shows that LJ, saying and uh and in a serious tone of voice, and overlapping with AP in line 6, wants to return to a serious frame without letting the hearer develop his humorous utterance, even though, at the beginning, LJ was the initiator of the humorous stance. Thus, AP's previous utterance (lines 5-6) can also be considered disaffiliative, a disaffiliation which is even more accentuated in line 8 , because AP does not take into account LJ's serious utterance. The same scenario is produced in lines 89: in overlap, AP keeps going and elaborates his imaginary world while LJ tries to remain serious. 
But line 9 is a decisive turn. While LJ tries at first to continue with his story, once again in overlap, he finally aligns and affiliates with AP, entering in AP's fictive world: in a smiling voice, he produces an ERS, i.e., the same fictitious reported speech, staging the same characters with a therapist asking his/her client if s/he likes gladiator movies. At that time, this humorous sequence becomes joint fantasising where the two participants jointly contribute to the elaboration of the imaginary world. LJ's contribution is ratified by AP laughing and overbidding (line 12). LJ laughs and finally goes back to his story in a serious mode.

This example is very interesting in several ways. Firstly, it shows that humour, even successful and jointly elaborated, is far from being self-evident. Here, the joint fantasising sequence created a kind of power relationship between the participants, the main speaker wishing to go back to a serious frame, while the hearer wants to stay within the humorous one. Thus, there should be negotiation between the participants. Secondly, in the whole data, it is the only example of the victory of humour in the case of such a power relationship between serious and humorous frames. One reason for this victory may be the fact that, at first, humour has been introduced by the speaker. Therefore, the hearer's humorous utterance is not a change of frame but the continuation of the one initiated by the speaker. Finally, this example is interesting because it informs about the way joint fantasising, more generally humour, and finally conversations, work. Trying to explain the occurrence of the power relationship before the joint fantasising itself shows the importance of being a main speaker (above all in a storytelling sequence which is considered asymmetric) and the distribution of roles. Indeed, three hypotheses could be made:

(i) concerning the conversation: it is because the participants are engaged in storytelling where LJ is the main speaker that he wants to keep the floor, and this is the reason why this conflict exists. But it is also because the two participants are engaged in a conversation and because they are close friends that, in the end, LJ accepts to leave the floor;

(ii) concerning humour: considering that AP's first utterance (line 5) is hardly framed as humorous - without transition at all, he only uses a specific tone of voice to frame his utterance (almost a whisper) - one could say that the less obviously framed as such humour is, the more uncertain its success is;

(iii) concerning joint fantasising itself: the more disconnected it is from the ongoing topic, thus increasing the risk of totally disrupting the conversation, the more it would have to be negotiated.

Finally, the fact that this joint fantasising has not been taken for granted but ends up succeeding highlights even more the symmetrical roles of the participants in such a sequence and justifies the use of humorous convergence. Indeed, this joint fantasising sequence begins to succeed when LJ, the speaker, ratifies AP's interventions and considers them legitimate, making AP co-speaker.

\section{Concluding remarks}

In this article, 51 examples of humorous success about or against "Others" as socioprofessional groups or foreign cultures have been analysed. Focusing on the targets has made it possible to analyse humorous sequences according to two different perspectives: the identities displayed by the participants through humour and the structure of a humorous sequence. 
To target "Others" leads to displaying two different identities: the 'victim of' identity and the 'better than' one. The analysis of the way these identities are displayed through humour has highlighted four elements:

(i) the humorous devices do not seem to be affected by the kind of identity displayed. Both identities involve exaggeration, pejorative lexicon and comparison, for instance;

(ii) the identities seem to have an impact on the form of humour produced. If teasing is present in both identities, self-deprecating humour only appears when the participants place themselves as victims. This finding is not only consistent with previous studies showing that humour can allow participants to manage delicate social actions but, in some ways, it also deepens these previous studies. Indeed, self-deprecating humour allows participants to blame "Others" while apparently targeting themselves or, at least, including themselves in the target. In other words, not only the speakers mitigate their reproaches, framing them humorously with various devices, but they also include themselves in the target;

(iii) the focus on the identities highlights the importance of shared knowledge. Both personal and cultural knowledge has to be known and shared by the participants for humour to succeed;

(iv) the focus on the target and the identities displayed through humour highlights both the structural aspect of humorous convergence when it appears and, even more, its relational aspect, depicting participants acting together against an external target.

Furthermore, focusing on successful humour highlights its heterogeneousness. Two different structures have emerged: a two-part structure and a three-part structure.

A two-part structure corresponds to a successful humorous sequence which is not developed. It refers to the restricted use of successful humour. In this case, the speaker produces humour and the hearer reacts positively (with laughter and/or positive feedback). The speaker ratifies such reaction, even implicitly, i.e., without explicitly rejecting it, which also marks the end of the humorous sequence. The conversation then restarts in a serious mode, this restart being initiated either by the speaker or by the hearer.

A three-part structure refers to humorous convergence. This notion can be considered a synonym of humorous co-construction or joint fantasising insofar as it highlights the escalation process of humour. However, humorous convergence also focuses on the interactional roles of the participants, showing that, from asymmetrical, they become symmetrical. Relying on previous studies and considering the present data, it has been shown that,

(i) laughter being cooperative but not collaborative (Davies 1984), a simple laugh from the hearer is not sufficient for humour to be developed. Laughter can lead to the success of humour but does not necessarily lead to a joint fantasising sequence. Thus, to be co-constructed, a humorous sequence requires active participation from the hearer;

(ii) this active participation requires active participation in return from the speaker, which can function as a ratification per se or which can be complemented by another ratification mark like laughter and/or feedback markers. A three-part structure thus requires active participation from both participants. It is worth noting that this active participation in return from the speaker is not only a pre-requisite for humour to be co-constructed but it also justifies the notion of humorous convergence. Indeed, if the speaker ratifies and overbids the hearer's utterance, he legitimates such intervention and therefore considers the hearer a co-speaker. 
Although different, these two structures have in common the speaker's ratification already pointed out in previous studies (Guardiola \& Bertrand 2013; Bertrand \& Priego-Valverde 2017) as an important element of the interactional convergence. This study shows that this ratification is also a central element both for successful humour and for humorous convergence. This result confirms, on the one hand, the fact that interactional convergence is a pre-requisite for humour to succeed and, on the other hand, that humorous convergence is a sub-type of interactional convergence.

In successful humour, the speaker's ratification legitimates the hearer's positive reaction to humour. The fact that he does not use this reaction as a springboard to develop his own humour shows that he confirms the hearer as such. By contrast, in a humorous convergence, the speaker's ratification is achieved by an overbid and/or can be added to another ratification mark. In so doing, the speaker legitimates the hearer's intervention as active participation in the ongoing humour, and therefore, makes him a full speaker.

More precisely, the analysis of the three-part structure has shown that joint fantasising sequences are also heterogeneous. Two different types have emerged. The first one is completely relevant to the ongoing topic and allows the participants to develop it. This is what example (4) shows. The second type, illustrated by example (5), is a joint fantasising sequence which creates a side sequence disconnected from the ongoing topic. While the escalation structure is the same in the two types of joint fantasising sequence, example (5) shows that, even when co-constructed, humour is not self-evident. All the perseverance from the hearer was required. Despite this perseverance, one can legitimately wonder if his humorous utterances would have succeeded if the speaker had not finally accepted it, playing along with the hearer's multiple attempts. This last example leads to a hypothesis: the more a joint fantasising sequence departs from the ongoing topic, at the risk of definitively interrupting it, the more it should be negotiated by the participants.

Furthermore, both examples (4) and (5) highlight the complementary roles or rights and duties of the speaker and of the hearer. Indeed, in example (4) the hearer needs clarification before entering in the humorous sequence delivered as self-deprecating. It shows that the speaker has to deliver all the sufficient information for the humour he produces to be understood and to allow the hearer to actively participate in it. This example thus highlights the speaker's duties. By contrast, example (5) highlights his rights: the right to keep the floor, in a certain way, without being disrupted. And even though in this example the humorous frame proposed by the hearer wins the power relationship between the two participants (the single example in the whole set of data), one cannot help thinking that, besides the fact that humour was introduced by the speaker, the speaker finally concedes providing his own active participation to better finish telling his story. Because this last finding concerns the analysis of a humorous sequence inserted in storytelling, it is consistent with previous studies showing the asymmetrical aspect of the storytelling. However, it needs to be deepened, analysed and compared with humorous sequences not inserted into storytelling in order to observe whether, as in storytelling, the distribution of the participants' roles also has a major importance and thus, an effect on the success or failure of humour.

To summarize, analysing successful humour and humorous convergence with the notions of "alignment", "affiliation" (Stivers 2008) and "interactional convergence" (Guardiola \& Bertrand 2013), on the one hand, shows how much the structural and the relational levels of humour are intrinsically linked to each other and, on the other hand, emphasises the roles the participants have, whether they are the speaker or the hearer, and the fact that these roles are not definitive and can change. These notions thus make it possible to highlight the interactional dynamics of humour in conversations. Indeed, in line with work considering that a conversation is a "joint activity" (Clark 1996), the question is: what does each participant do 
to achieve humour? Taking into account, first, that humour is as much a conversational activity as storytelling and, second, that several instances of humour analysed here are produced in storytelling, the methodology used to analyse storytelling has been applied to humour.

Such methodology has confirmed what was argued in the second section of this article:

(1) Interactional convergence is a pre-requisite for humour to succeed.

(2) This success can manifest itself in two ways:

(2a) a two-part structure where the speaker produces humour and the hearer reacts positively. This reaction is ratified, even implicitly, by the speaker. In this structure, the respective roles of speaker and hearer are observed. It is thus successful humour;

(2b) a three-part structure where the speaker produces humour, the hearer plays along with the speaker's humour and the speaker overbids the hearer's utterance. Here, not only does the speaker ratify the hearer's intervention but he also considers it legitimate. In this case, the asymmetrical roles of speaker and hearer are suspended and both participants are co-speakers. This structure refers to humorous convergence.

The study presented here is the first step of a larger project on humorous convergence. Further analyses are needed in order to refine this notion. To this end, the data has to be expanded, including, for instance, the other kinds of target of the humorous sequences, or taking into account more humorous sequences which are not inserted into storytelling.

\section{Acknowledgements}

The author wishes to thank Roxane Bertrand and the two anonymous reviewers for their comments and feedback on the present paper.

\section{Notes}

${ }^{1}$ An aside is close to Jefferson's (1972) side sequence. It is also a short break in the ongoing activity. More specifically, in an aside, as in the example here, participants are engaged in a metacommunicative activity.

${ }^{2}$ While a fictitious RS, produced by the speaker, refers to a "ventriloquized voice" (see Tannen 2010), ERS is produced by the hearer.

${ }^{3}$ This pattern of reaction has been quantified and systematically analysed in Bertrand \& Espesser (2017).

\section{Conventions of transcription}

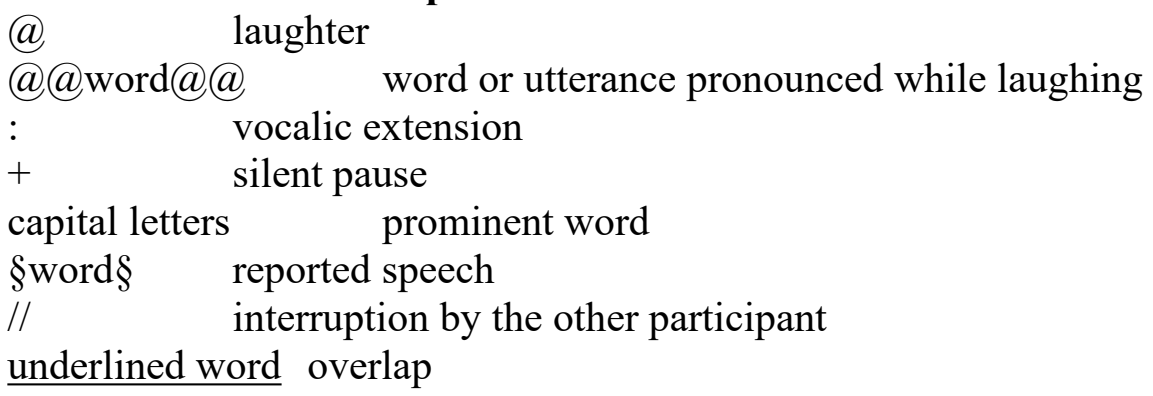




\section{References}

Archakis, A. \& Tsakona, V. (2005). 'Analyzing conversational data in GTVH terms: A new approach to the issue of identity construction via humour'. Humor 18 (1), pp. 41-68.

Attardo, S. (2001). 'Humor and irony in interaction: from mode adoption to failure of detection', in Anolli, L., Ciceri, R. \& Riva, G. (eds.), Say not to Say: New Perspectives on Miscommunication. Amsterdam: IOS Press, pp. 166-185.

Bavelas, J. B., Coates, L. \& Johnson, T. (2000). 'Listeners as co-narrators'. Journal of Personality and Social Psychology 79, pp. 941-952.

Béal, C. \& Mullan, K. (2013). 'Issues in conversational humour from a cross-cultural perspective: comparing French and Australian corpora', in Peeters, B., Mullan, K. \& Béal C. (eds), Cross-culturally Speaking, Speaking Cross-culturally. Newcastle: Cambridge Scholars, pp. 107-139.

Bell, N. (2015). We Are Not Amused. Failed Humour in Interaction. Berlin, Boston, Munich: Mouton de Gruyter.

Bertrand, R., Blache, P., Espesser, R., Ferré, G., Meunier, C., Priego-Valverde, B. \& Rauzy, S. (2008). 'Le CID - Corpus of Interactional Data-Annotation et exploitation multimodale de parole conversationnelle'. Traitement Automatique des Langues 49, pp. 105-134.

Bertrand, R. \& Priego-Valverde, B. (2011). 'Does prosody play a specific role in conversational humour?'. Pragmatics and Cognition 19, pp. 333-356.

Bertrand, R. \& Priego-Valverde, B. (2017). 'Listing practice in French conversation: From collaborative achievement to interactional convergence', Discours 20 https://journals.openedition.org/discours/9315

Bertrand, R. \& Espesser, R. (2017). 'Co-narration in French conversation storytelling: A quantitative insight'. Journal of Pragmatics 111, pp. 33-53.

Bigi, B. (2015). 'SPPAS - Multi-lingual Approaches for the Automatic Annotation of Speech'. The Phonetician 111-112, pp. 54-69.

Blache, P., Bertrand, R. \& Ferré, G. (2009). 'Creating and exploiting multimodal annotated corpora: the ToMA project', in Kipp, M., J.C. Martin, J.C., Paggio, P. \& Heylen, D. (eds.). Multimodal Corpora. From Models of Natural Interaction to Systems and Applications, Berlin, Heidelberg: Springer-Verlag, pp. 38-53.

Boersma, P. \& Weenink, D. (2009). 'Praat:Doing Phonetics by Computer'. (Version 5.1.05) [Computer program]. http://www.praat.org/

Boxer, D. \& Cortés-Conde, F. (1997). 'From bonding to biting: Conversational joking and identity display'. Journal of Pragmatics 27, pp. 275-294.

Coates, J. (2007). 'Talk in a play frame: More on laughter and intimacy', Journal of Pragmatics 39, pp. 29-49.

Chovanec, J. (2015). 'Participant roles and embedded interactions in online sports broadcasts', in Dynel, M. \& Chovanec, J. (eds.). Participation in Public and Social Media Interactions. Amsterdam and Philadelphia: John Benjamins, pp. 67-95.

Clark, H. H. (1996). Using Language. Cambridge: Cambridge University Press.

Davies, C. E. (1984). 'Joint joking: Improvisational humorous episodes in conversation'. Proceedings of the Tenth Annual Meeting of the Berkeley Linguistics Society, pp. 360-371.

Drew, P. (1987). 'Po-faced receipts of teases'. Linguistics 25, pp. 219-253.

Goodwin, C. (1984). 'Notes on story structure and the organization of participation', in Atkinson, M. \& Heritage, J. (eds.), Structures of Social Action, Cambridge: Cambridge University Press, pp. 225-246.

Guardiola, M. \& Bertrand, R. (2013). 'Interactional convergence in conversational storytelling: when reported speech is a cue of alignment and/or affiliation'. Frontiers in Psychology 4: 705, pp. 1-17. doi: 10.3389/fpsyg.2013.00705 
Haugh, M. (2010). 'Jocular mockery, (dis)affiliation, and face', Journal of Pragmatics 42, pp. 2106-2119.

Haugh, M. (2011). 'Humour, face and (im)politeness in getting acquainted', in Davies, B., Haugh, M., \& Merrison, A. (eds.), Situated Politeness, London: Continuum, pp. 165-184.

Haugh, M. (2014). 'Jocular mockery as interactional practice in everyday Anglo-Australian conversation'. Australian Journal of Linguistics 34 (1), pp. 76-99.

Haugh, M. (2017). 'Jocular language play, social action and (dis)affiliation in conversational interaction', in Bell, N. (ed.), Multiple Perspectives on Language Play, Boston: Mouton De Gruyter, pp. 143-168.

Hay, J. (1995). Gender and Humour: Beyond a Joke. Master thesis, Victoria University of Wellington.

Hay, J. (2000). 'Functions of humour in the conversations of men and women'. Journal of Pragmatics 32 (6), pp. 709-742.

Hay, J. (2001). 'The pragmatics of humour support'. Humor 14 (1), pp. 55-82.

Holmes, J. (2006). 'Sharing a laugh: Pragmatic aspects of humor and gender in the workplace', Journal of Pragmatics 38, pp. 26-50.

Jefferson, G. (1972). 'Side sequences', in Sudnow, D. N. (ed.) Studies in Social Interaction, New York: Free Press, pp. 294-338.

Jefferson, G. (1978). 'Sequential aspects of storytelling in conversation', in Schenkein, J. (ed.), Studies in the Organization of Conversational Interaction. New York: Academic, pp. 219248.

Kerbrat-Orecchioni, C. (1986). L'implicite, Paris: Armand Colin.

Kotthoff, H. (2002). 'Irony, quotation, and other forms of staged intertextuality', in Graumann, C. \& Kallmeyer, W. (eds.), Perspective and Perspectivation in Discourse. Amsterdam: John Benjamins, pp. 201-233.

Kotthoff, H. (2007). 'Oral genres of humor: on the dialectic of genre knowledge and creative authoring'. Pragmatics 17(2), pp. 263-296.

Lampert, M. \& Erving-Tripp, S. (2006). 'Risky laughter: Teasing and self-directed joking among male and female friends'. Journal of Pragmatics 38, pp. 51-72.

Mills, C.B. \& Babrow, A.S. (2003). 'Teasing as a means of social influence'. Southern Communication Journal 68 (4), pp. 273-286.

Norrick, N. (1993). Conversational Joking: Humour in Everyday Talk. Bloomington: Indiana University Press.

Norrick, N. (1994). 'Involvement and joking in conversation'. Journal of Pragmatics 22 (3-4), pp. $409-430$.

Norrick, N. (2000). Conversational Narrative: Storytelling in Everyday Talk. Amsterdam: John Benjamins.

Norrick, N. (2003). 'Issues in conversational joking'. Journal of Pragmatics 35, pp. 13331359.

Norrick, N. (2007). 'Conversational storytelling', in Herman, D. (ed.) The Cambridge Companion to Narrative. Cambridge: Cambridge University Press, pp. 127-141.

Norrick, N. (2010). 'Humour in interaction'. Language and Linguistics Compass 4 (4), pp. 232-244.

Otake, N. \& Cutler, A. (2013). 'Lexical Selection in Action: Evidence from Spontaneous Punning'. Language and Speech 56 (4), pp. 555-573.

Priego-Valverde, B. (2003). L'humour dans la conversation familière: description et analyse linguistiques, France, L'Harmattan.

Priego-Valverde, B. (2006). 'How funny it is when everybody gets going! A case of coconstruction of humour in conversation'. Círculo de lingüística aplicada a la comunicación (clac). www.ucm.es/info/circulo/no38/alsdic.pdf 
Priego-Valverde B. (2007). 'Self-disparaging humor in conversation', in Popa, D. \& Attardo, A. (eds), New Approaches to the Linguistics of Humour, Galaţi, Romania: Editura Academica. pp. 15-34.

Priego-Valverde, B. (2009). 'Failed humour in conversation: a double voicing analysis', in Norrick, N. \& Chiaro, D. (eds.), Humour in Interaction, Amsterdam: John Benjamins, pp. 165-183.

Priego-Valverde, B. (2016). 'Teasing in casual conversations: an opportunistic discursive strategy', in Ruiz-Gurillo L. (ed.), Metapragmatics of Humour, Amsterdam: John Benjamins, pp. 215-233.

Selting, M. (2000). 'The construction of "units" in conversational talk'. Language Society 29, pp. 477-517.

Selting, M. (2017). 'The display and management of affectivity in climaxes of amusing stories'. Journal of Pragmatics 111, pp. 1-32.

Stallone, L. \& Haugh, M. (2017). 'Joint fantasizing as relational practice in Brazilian Portuguese interactions'. Language \& Communication 55, pp. 10-23.

Stivers, T. (2008). 'Stance, alignment, and affiliation during storytelling: When nodding is a token of affiliation'. Research on Language and Social Interaction 41 (1), pp. 31-57.

Straehle, C. (1993). "Samuel?" "Yes dear?" Teasing and conversational rapport', in Tannen, D. (ed.), Framing in Discourse, Oxford: Oxford University Press, pp. 210-230.

Tannen, D. (2007). Talking voices. Repetition, Dialogue, and Imagery in Conversational Discourse. Cambridge: Cambridge University Press.

Tsakona, V. (2018). 'Online joint fictionalization', in Tsakona, V. \& Chovanec, J. (eds.), The Dynamics of Interactional Humour, Amsterdam: John Benjamins, pp. 229-255.

Tannen, D. (2010). 'Abduction and identity in family interaction: Ventriloquizing as indirectness', Journal of Pragmatics 42 (2), pp. 307-316.

Vincent, D., \& Dubois, S. (1997). Le discours rapporté au quotidien. Québec: Nuit Blanche éditeur. 